\title{
Experimental Organism Adenocarcinoma Arising in Fibroadenoma
}

National Cancer Institute

\section{Source}

National Cancer Institute. Experimental Organism Adenocarcinoma Arising in

Fibroadenoma. NCI Thesaurus. Code C154892.

A malignant glandular neoplasm that arises from a pre-existing benign fibroadenoma. 